\title{
Yunan Demokrasisinin Kavramsal Yönü Ve Toplumsal Arka Planı
}

\section{Özet}

Bu çalışmada, Yunan'da M.Ö 4. ve 5. yy'larda görülen demokrasi deneyimine dair bir anlama çabası ortaya konulacaktır. Bu çabada özellikle Yunan demokrasisini anlamada yöntem olarak, "kavramsal boyut" ile "toplumsal ilişkiler ve toplum yapısı" bütünsel bir değerlendirmeyle ele alınmaya çalışılmaktadır. Bu anlamda sosyolojik ele alış yöntemiyle çalışma oluşturulmaya hazırlanmıştır.

Anahtar Kelimeler: Siyaset, Yunan toplumu, demokrasi, yurttaşlık

\section{Athen Democracy of Conceptual Side and Sociogical Backgrounds}

\begin{abstract}
In this work text, it was brought effort to understanding for democracy experience up in Athen BC 4-5th century. This effort was studied in evaluated in order to understanding Athen democracy as a process specially integral "conceptual dimension" and "social relations and social structure". In a sense this work text was occurred by process evaluation sociologically.

Keywords: Politics, Greek society, democracy, citizenship

\section{Giriş}

Günümüz toplumundan, klasik demokrasiye bakıldığında, Yunan toplumunda görülen demokrasi deneyiminin hangi özellikler sergilediğinin anlaşılabilmesi için klasik demokrasinin kavramsal özelliklerinin üzerinde durulduğu kadar Yunan'da toplumsal ve siyasal koşulların da ele alınması gerekmektedir. M.Ö. 4-5 yy'larda karşımıza çıkan demokrasi yönetiminin kavramsal yönü ve toplumsal özellikleri bağlamında konuyu ele alma çabası içinde olunacaktır. Bu doğrultuda, Yunan demokrasisinin düşünsel boyutu, ifade edilen belli kavramlar ve açıklamalar çerçevesinde ele alınacaktır. Dolayısıyla, halk kavramı, yurttaş kavramı ele alınacaktır. Bunun yanında
\end{abstract}

${ }^{1}$ Dr., Afyon Kocatepe Üniversitesi, Fen Edebiyat Fakültesi, Sosyoloji Bölümü. aslihanakkoc@aku.edu.tr 
Yunan'da siyasal haklar denildiğinde bunun anlamı nerede başlayıp, nerede bitmektedir. Yunan'daki demokrasi deneyimini anlama çabasında toplumsaltarihsel ilişkiler göz önüne alınmadan klasik demokrasiye dair bir değerlendirme yapma imkanı sınırlı gözükmektedir. Bu nedenle "kavramsal boyut" ve "toplumsal-tarihsel gerçeklikler" ekseninde Yunan demokrasisini ele almas1 gerekecektir.

Çalışmada, Yunan'da görülen demokrasi yönetimine dair bir anlama çabası söz konusudur. Bu ele alma çabasında yöntem olarak "kavramsal gerçeklik boyutu" ve "toplumsal gerçeklik boyutu" olmak üzere her iki alana dair bilgiler göz önüne alınarak değerlendirilecektir. Yunan demokrasisini sosyolojik bir ele alış yöntemiyle değerlendirme çabasında; tarihsel-siyasal bir süreç olarak ve günümüzün modern demokrasiyle olan ilişkisi açısından konunun kavramsal-ideal yönü kadar toplumsal-tarihsel süreçler açısından da ele alınması önem taşımaktadır. Dolayısıyla çalışmada, Yunan demokrasisinin her iki gerçeklik boyutunun da göz önüne alınarak incelenmesi amaçlanmaktadır.

\section{Demokrasi Kavramı}

Demokrasinin düşünsel ve kavramsal anlamına öncelikle bakarsak; örneğin Aristoteles (Aristoteles,2010: 93-94), demokrasiyi birikmiş bir zenginliğe sahip olmayan varlıksızların yönetime sahip olması şeklinde açıkladığı görülmektedir. Kavramsal boyutta demos ve kratos kelimelerinin anlamına baktığımızda ise, demos kavramı kentte yaşayan yığınlar, kalabalıklar ve bunun yanında, yoksulları da kapsadığı (Sartori, 1996: 22) ve sıradan insanlar, alt tabaka ve din adamlarına karşılık geldiği (Arblaster, 1999: 27) görülmektedir. Kratos ise, güç ve egemenlik olarak açıklandığ görülmektedir. Demos'un M.Ö. 5 yy'da ekklesia'da toplanan Atinalı topluluklar anlamında kullanıldığı vurgulanmaktadır. Ancak, yığın ve çoğunluk anlamlarının yanı sıra halk kavramının farklı anlamlarla da karşımıza çıktığını Sartori (1996: 23) vurgulamaktadır. Halk, kimi zaman herkes anlamına gelmektedir, kimi zaman aşağı sınıf anlamını taşır bunun dışında halkın, bölünmez bir varlık organik bir bütün olarak açıklandığı da görülmektedir. Öyleyse, ilk olarak Eski Yunan'da gördügümüz demokrasinin uygulamada nasıl bir anlamda karşımıza çıktığının üzerinde durulmasi gerekmektedir.

$\mathrm{Bu}$ ele alma çabasında kavramsal boyutun yanı sıra toplumsal ilişkiler açısından uygulama düzeyinde demokrasinin nasıl gerçekleştiğini anlamak için Yunan toplum yapısını ve farklı sınıfları ele alma gereği söz konusudur. Dolayısıyla, Yunan demokrasisinde halk kavramının ve yurttaş kavramının toplumsal manadaki karşılıklarını da irdeleme gereği duyulmuştur. Yunan demokrasisini ele alma çabamızda, meselenin 
kavramsal-ideal yönü açısından olduğu kadar toplumsal boyutu açısından da ele alınması gereği söz konusudur.

\section{Halk}

Yunan kentinde aristokrasiden tiranlığa ve demokrasiye kadar farklı uygulamalar görülmekle beraber Yunan kentini karakterize eden yönetim demokrasidir. Halk yönetimi olarak kavramsal boyutta tanımlanan demokrasinin toplumsal yaşamdaki açılımı nasıl gerçekleşmektedir. Halk, kavramının Yunan toplumunda yer alan bütün insanları işaret etmediği görülecektir. Halk kavramının içeriğinde sadece özgür insanlar vardır (Sartori, 1996: 24). Yunan'da halk (demos) kavramı, anlam olarak köleleri içermemektedir. Köleler “... köle sahiplerinin malı ya da canlı bir araç olmaktan ötede sayılmadıklarından, haliyle 'insan' kategorisi içinde de değerlendirilmeyecek ve zaten özgürlük sözcügüyle ilişkilendirilmeyecektir." (Yalçınkaya, 2011: 43).

Yunan'da halk kavramına toplum yapısı açısından bakmak gerekecektir. Atina kentinde halk (demos) kavramının karşılığı olarak farklı toplumsal sınıflar karşımıza çıkmaktadır. Eupatrid; büyük toprak sahibi soylular, demiurgoi; ticaretle ve zanaatla uğraşan kentli orta sınıf, georgoi; az topraklı yoksul köylü, thethes; toprakları ve belli bir işleri olmayan kentli emekçiler olarak ayrıldığı görülmektedir (Ağaoğulları, 2013: 24 ve Yalçınkaya, 2011: 36). Bununla birlikte soylular da, kendi içlerinde eupatridler: iyi doğmuşlar, geomarlar: toprak beyleri, hippeisler: atlllar olarak ayrıldıkları görülecektir (Ağaoğulları, 2013: 22). Bu saydığımız kesimlerin eşlerinin ya da kızlarının, siyasal ve toplumsal alana dahil edilmediği, evlerinde kapalı bir yaşam sürdürdükleri anlaşılmaktadır. Ağaoğulları, kadınların hiçbir zaman yurttaşlık statüsüne erişemediğini belirtmektedir (2013: 20). Yabancılar da Yunan'da saydığımız kesimlerden olamayacaklarına göre siyasal alandan uzaktırlar.

Yunan toplum yapısına bakıldığında; demokrasi kavramı çerçevesinden ele alındığında, kadınlar ve yabancılar da kısmen özgür insanlardır, halk kavramının içindedir, fakat siyasal haklardan yoksundurlar. Aslında; kadınlar ve yabancılar özgür insan olarak tanımlanırlar ve halk kavramının içinde tanımlanırlar öyleyse, Yunan'da halk (demos) kavramı, anlam olarak siyasal haklara sahip olanları tanımlamamaktadır. Bu anlamda Yunan'da halk kavramı toplumsal kuşatıc1lık anlamında sorunlu ve toplumsal eşitsizliği vurgulayan bir anlam içeriğine sahiptir. 


\section{Yurttaşlık ve Siyasal Haklar}

Yunan'da kavramsal düzeyde yurttaş kavramı, siyasal hakların sahiplerini işaret etme anlamında kullanılmaktadır. Bununla birlikte, Yunan'da yurttaş kavramı, günümüzün yurttaş kavramı ile farklılıklar taşımaktadır. Günümüzde modern demokrasilerde yurttaşlar, sınırlı

istisnalar $^{2}$ dışında toplumdaki tüm insanları işaret etmektedir. Yunan kentinde yurttaşlık sürecini ve siyasal katılım hakkını anlayabilmek için kent-devletinin toplumsal ve siyasal özelliklerini de göz önünde bulundurmak gerekecektir.

Yunan'daki demokrasi bir yurttaşlar yönetimi olarak karşımıza çıkmaktadır. Yurttaşlar kentin yönetimine katılmaktadırlar. Bununla birlikte, kentin yönetimine katılım kavramının anlamının toplumsal gerçeklikteki görünümünün üzerinde durmak gerekecektir. Bunun yanı sıra yurttaş, yurttaşlar yönetimi ve siyasal katılımın toplumsal alanda karşımıza nasıl çıktığını ele almak gerekmektedir. Bu noktada farklı kent-devletleriyle karşılaştırarak ele almak da yararlı olacaktır. M.Ö. 4-5. yy'larda eski Yunan coğrafyasında birçok kent devleti olmakla beraber, bunlar içinde öne çıkanlar Atina ve Sparta'dır. Sparta oligarşiyle karakretize edilmektedir. Ancak Sparta'da da yurttaşlar mevcuttur. Bu bahsedilen kentlerde yönetimde öne çıkan özellik "yurttaşlar yönetimidir". Öyleyse Yunan kentdevletinde görülen demokrasiyi Sparta'daki oligarşiden ayıran nedir, sorusunu sormak gerekecektir. Dolayısiyla, Yunan demokrasisini toplumsalsiyasal düzeyde dönemin ilişkileri ekseninde ele alma gereği söz konusudur.

Dolayısıyla, toplumsal süreçler ve toplum yapısı ekseninde konuya yaklaş1lması gerekmektedir. Yurttaşlar, siyasal katılım sahibi olarak karşımıza çıkmaktadır. Kentin yönetimine katılımın, uygulamada kentin siyasal ve toplumsal yaşamında birçok farklı role karşıllk geldiği görülür. Memurluk, askerlik, vergi yükümlülügü̈, seçme hakkı ve yönetici seçilme hakkı, dava açma hakkı, yargılama hakkı, halk meclisinde yer alma hakkı ve arkhon olma hakkı gibi kentin siyasal yaşamında rol perspektifinin genişliğine rağmen her birinin yurttaşlık olarak nitelendiği görülmektedir. Yurttaşlar kendi içlerinde türdeş değildir, ekonomik ve toplumsal ayrımlar yurttaşlar için de geçerlidir (Ağaoğulları, 2013: 20). Kentin siyasal yaşamındaki farklı rollerin, yurttaşlara servetleri ölçüsünde dağıtıldığ 1 görülmektedir. Yoksul kesim thetesler, sadece halk meclislerinde rol alabilmekteyken, soylu toprak zengini ya da ticaret zengini, yönetici

\footnotetext{
${ }^{2}$ Akli yetileri tam olmayanlar, farklı uyruklara mensup olanlar gibi. Ayrıca 18 yaşın altındakilerde oy kullanamaz fakat bu kişiler potansiyel birer seçmendir.
} 
görevine gelebilmektedir. Arhon olabilmek için birinci sınıftan olmak bir zorunluluktur (Ağaoğulları, 2013: 32).

Yunan kenti, bir anlamda yurttaşlar yönetimi olarak karşımıza çıkmaktadır. Bunun yanında, Yunan'da tarihsel süreçte yurttaşlık anlayışına bakılırsa, yurttaşlık; öncelikle soy temelli bir belirleyiciliğe sahiptir. M.Ö. 594'de Solon anayasa ve yasalar hazırlatarak, yurttaşlık anlayışını bu kez servet ölçüsünde temellendirmiştir. 500 kile buğday, eşdeğerinde zeytinyağ 1 üreten veya eşdeğer şarap üretenler birinci sınıf, 300 kile sahibi olanlar ikinci sınıf, 150 kile sahibi olanlar üçüncü sınıf, yıllık geliri 150 kilenin altında olanlar ise dördüncü sınıfı oluşturuyorlardı (Şenel, 2011: 125). Yunan'da yeni yasalara göre, siyasal haklar, askerlik, vergi gibi yükümlülükler bu sinıflara göre yeniden düzenlenmiştir (Ağaoğulları, 2013: 30-31). Ancak burada yine toplum yapısına göz atmak yerinde olacaktır. Çünkü Yunan'da ekonomik yapıyla ilişkili bir sınıfsal hiyerarşi söz konusudur. Bu doğrultuda, ekonomik imkanlar, servetin dağılımı zenginliğin karşılığı toplumda soy bă̆ profili çizmeye yeterli olmayacaktır.

Yunan'da siyasal haklara sahip olanların kapsamının Yunan tarihinde dönemden döneme değiştiği görülmektedir. Yurttaşlık kavramının toplumsal ve siyasal olaylara bağlı olarak değişkenliği söz konusudur. Ancak yurttaşlık kavramının toplumsal anlamı değişmemektedir. Yurttaşlık bireylere bir hak olarak değil, mülk karşıllı̆̆ ya da zaman zaman yapılacak bir iş yükü karşıllı̆ 1 verilmektedir (Canfora, 2010: 25-26). Atina kentinde halk kavramının; varolan sınırlılı̆̆ ve toplumsal eşitsizliği yanında, yurttaşlık çerçevesi de dönemden döneme değişkendir ve sınırlılıklar taşır.

Yurttaşlık çerçevesinin değişkenliğinin üzerinde durmak gerekirse, Yunan'da yurttaşlık sınırlarının genişlediği bir diğer dönem de Pers tehlikesinin arttı̆g dönemdir. Yurttaşlık ve memurluk sınırları bu süreçte genişlemektedir. Bunun nedeni “...herkesin polisin korunmasına katkıda bulunması zorunluluğu..." olarak ifade edilmektedir (Ağaoğulları, 2013: 43). $\mathrm{Bu}$ süreçte theteslerin, arkhon olmalarının kabul edildiği ve memurlukların tüm sınıflara açıldığı da vurgulanmalıdır. Hatta Ağaoğulları, Pers savaşlarının Atina'da demokrasinin gelişmesinde ve yerleşmesinde etkili olduğu yorumunu yapmaktadır. Perslere karşı sürekli birlik halinde kalabilmek için Attik-Delos Birliğini kurarak bu birliğin imkanlarıyla Yunan'ın daha da zenginleştiği ve bu imkanların siyasal, askeri, ekonomik ve kültürel gelişmelere yol açtığı vurgulanmaktadır. Özellikle de Perikles dönemiyle, bütün yurttaşların siyasal yaşama katılımının sağlanması yönünde kararların alındığı görülecektir. Devlet görevlerine katılanlara ücret ödenmesi yoluyla yoksul kesimin devlet görevlerine gelememe sorununu Perikles'in aşmaya çalıştığ görülecektir. Bütün bunlara rağmen Ağaoğulları (2013: 43-47), Solon ve Perikles'in siyasal yaşama katılımın imkanlarını geliştirmelerine ve yurttaşların siyasal özgürlüğe sahip olmalarına rağmen 
devletin(polis) dönemin anlayışında belirleyiciliğe sahip olduğunu ve siyaset karşısında bireylerin hiçbir hakka sahip olmadığını vurgulamaktadır.

\section{Özgürlük}

Yunan'da özgürlük kavramını ele alacak olursak, Yunan kentinin, toplumsal-siyasal diğer özellikleri gibi özgürrlük kavramından anlaşılan da kentin özgür oluşudur. Bu anlamda, özgürlük kavramı da kentle bütünleşik bir anlamı içeriğine sahiptir. Bireysel bir özgürlük anlamını içermediği, dolayısıyla kente ve siyasete ilişkin bir özgürlük anlayışının egemen olduğu görülecektir. "Antik çağın kent topluluklarında, özgürlük devlet iktidarına karşı koyabilme biçiminde düşünülmezdi çünkü devlet olgusu yoktu. Özgürlük iktidarın kollektif kullanımına katılım olarak ele alınırdı.” (Sartori, 1996: 316). Ayrica, Hobbes (2013:166-167) da, "Atinalilar ve Romalilar özgürdüler;.....tek tek insanlar kendi temsilcilerine direnmek özgürlüğüne sahip oldukları için değil; onların temsilcisi, başkalarına direnme ve onları istila etme özgürlüğ̈̈ne sahip..." olduğunu vurgulamaktadır.

\section{Kent Kimliği}

$\mathrm{Bu}$ noktada, Atina ve diğer kent devletlerinin bir özelliği olarak kentin kollektifliği dikkat çekmektedir. Yunan coğrafyasında her kişinin, bulunduğu kentin kimliğiyle bütünleştiği ve bu anlamda kent devletlerinde kollektif bir yapının olduğu yorumu yapılabilir (Çaha, 2010; 21). Ağaoğulları (2013:16) da kent devletinin, askeri, dini, siyasi, ekonomik bir bütünlük olduğunu vurgulamaktadır. Hatta, kentte yaşayanlar için kendi yaşamları kentin varlığıyla, düzeniyle anlamlıdır. Kentin dışında insan, bir anlamda hiçbir şeydi, köle ya da çeşitli haklardan yararlanamayan yabancı olarak yaşamını sürdürecekti. $\mathrm{Bu}$ anlamda kent dışı yaşam alanının neredeyse olmayış1, kentte dayanışma duygusunu da geliştiren unsurlardan biri olarak değerlendirilebilir. Ait oldukları kentin kimliği, kentlilik, dayanışma duygusu önem taşır, çünkü kenti dışında hayatta kalma imkanları sınırlıdır.

Bunun yanı sıra, Arnhart (2008: 36), Atina kültüründe, toplumsal olayları birbirinden ayrıştırmadan kent meselesi çerçevesinde algılandığını vurgulamaktadir. Yunan toplumunda, bu anlamda toplumsal-siyasal bütünsel bir algının olduğunu ifade etmektedir. ${ }^{3}$ Yunan'da insanların yaşamının; "siyasal alan", "özel alan ya da bireysel alan" gibi ayrımlara gitmeden bir bütün olarak algıladıkları görülmektedir (Yalçınkaya, 2011: 45). Ayrıca

\footnotetext{
${ }^{3}$ Arnhart, Yunan toplumuyla günümüz Amerikan kültürünü karşılaştırarak, Yunan toplumunda insanların Amerika kültüründeki gibi bireysel olmadığını belirtmektedir(Arnhart, $2008 ; 36)$.
} 
Sartori (1996) de, kentteki bireylerde, bireysel bir kimlik algisının olmadığını vurgulamaktadır. Bunlara ek olarak, dil ve zihin dünyası anlamında da, kentin bütünleşik algısının izleri görülmektedir.

"Latince özel anlamına gelen privatus "mahrum edilmiş" (private, mahrum etme fiilinden) demektir ve bu terim toplulukla ilişkisi açısından bazı eksiklikleri ve noksanları olanları belirtmek için kullanılır. Yunanca idion (özel), koinon (ortak öge) tersine, daha aşırı bir biçimde mahrumiyet ve büyük bir yoksunluğu ifade etmektedir. Buna uygun olarak idiotes küçültücü bir sözcüktür, polites olmayan (vatandaş olmayan, bu nedenle de yalnız kendisiyle ilgilenen, cahil, değersiz ve kaba adam anlamına gelir) demektir." (Sartori, 1996: 309).

Zihin ve anlam dünyasının da kentin toplumsal yapısı gereği ortaya çıkan kollektifliği vurguladığı görülmektedir. İnsan, toplulukla birlikte anlamlı görülmektedir. $\mathrm{Bu}$ topluluğun bir parçası olmamak dönemin koşullarında birçok şeyden de mahrum olmayı da beraberinde getirdiği anlaşılmaktadır.

Bunun dışında; Yunan coğrafyasında bireylerin kentle her anlamda bütünleşmesi, başka bir ifadeyle; toplumsal-siyasal bütünsel bir kimlik yaratılması sonucu Yunan kimliğinin oluştuğu belirtilebilir. Ayrıca bu dönemlerde, Yunan ve Pers karşılaşmaları söz konusudur. Persler'den gelebilecek saldırılara karşı "bütünsel kent kimliği" oluşumunun etkili olduğu belirtilmelidir. Perslerle yapılan savaşlarda, Atina ve diğer Yunan kentleri birlikte hareket ederek farklı bir bilinç ve kimliğin yaratılması imkanı da olmuştur.

\section{Kölelelik}

Kavramsal olarak Yunan toplumunun bir parçası olarak açıklanmayan kölelerin üzerinde de durmak gerekmektedir. Çünkü Eski Yunan'da demokrasinin anlaşılması çabasında köleliğin düşünsel anlamı ve toplumsal boyuttaki anlamını ve rolünü incelemek gerekecektir. Kölelik kavramını anlamak için; köleliğin, Yunan düşüncesinde nasıl açıklandığını ve bunun yanı sıra, Atina kentindeki toplumsal rolünü ele almak gerekecektir. Köleliğin, Yunan düşüncesinde nasıl açıklandığı konusuna değinilecek olursa; öncelikle Platon'un Devlet adlı eserinde de görüldüğü gibi farklı toplumsal sınıftan olanların farklı bir madene karş1lık olduğu ifade edilir. "...sizi meydana getiren tanrı, aranızdan önder olacak yetenekte olanların mayasına altın katmıştır; bu yüzden, değeri en yüksek olanlar onlardır. Yardımcıların mayasına gümüş̧; çiftliklerle öbür sanat sahiplerinin mayasına ise demir ve tunç katmıştır." (Platon, 2002: 132). Yönetimde bilgin ve filozof kişilerin olmasından yanadır. Platon bu fikri bütün kitabı boyunca vurgular. Bu çizgi Aristoteles ile devam eder, “...'doğası gereği köle olan'

bir başkasına ait olabilen ve bu yüzden bir başkasına ait olan, aklını kullanma yeteneği, anlayabilecek, fakat tam bir akla sahip olamayacak kadar olan kişidir." (Aristoteles, 2010: 19). "Köleler, yabancı zanaatçılar yanı sıra 
siyasal erdemleri geliştirmeye elverişli olmayan işlerde çalışan, erdemleri körelmiş yerli özgür zanaatçılar ile gündelikçilere de siyasal hakların tanınmaması gerektiğini ileri sürer." (Şenel, 2011;185). Aristoteles'in ele alışı, köleliğe dair açıklamaları köleliği ve toplumsal eşitsizliği meşrulaştırmaktadır.

Kölelik kurumu ve Yunan'da görülen diğer toplumsal eşitsizlik biçimlerinin oluşumunda Yunan düşüncesiyle toplumsal süreçler arasındaki paralellik dikkat çekmektedir. Aristoteles ve Platon'un eserlerinde toplumsal yaşamda yeralan tüm insanların çeşitli nedenler ileri sürülerek kategorik ayrımlara tabi tutularak açıklanması, ve bu açıklama biçimlerinin toplumsal hayata da yansımasıyla sonuçlanmıştır. İnsanlar arası farklılıklar; fiziksel farklılıklar, toplumsal farklılıklar; farklı ekonomik ve sosyal statülere sahip olma gibi birçok farklılık biçimi, belli kesimlerin ayrıcalıklı olduğunu ifade etmede kullanılan bir argümana dönüşmektedir. "Toplumsal ayrımcıllğın" düşünce boyutuyla haklılaştırılarak, toplumsal manada devam etmesinde ve doğal görülmesinde rol oynamıştır.

Toplumsal-tarihsel süreçler açısından ise kölelik; Yunan'da ilk dönemler borç köleliği şeklinde görülecektir. Tefeciden borç alıp ödeyemeyen köylülerin (vatandaş) kendilerini ve ailelerini rehin göstermesiyle başladığı ifade edilecektir. Solon'un borç köleliğini ortadan kaldırdığı ve farklı sınıflar arası ekonomik ve siyasal çatışmayı engellemeye yönelik davrandığı görülecektir (Şenel, 2011: 124-125). İlk dönemlerde örneğin Solon döneminde kölelik çok önemli bir kurum değildir (Yalçınkaya, 2011: 39). Hatta Solon borç köleliğini kaldırmıştır. Köleliğin esas anlamı, yeni bir bölgenin elde edilmesi ve ele geçen ganimetlerle birlikte, esirlerin köle olarak toplumda kullanımına dayanmaktaydı. $\mathrm{Bu}$ anlamda kölelik, demokrasinin oluşumuyla bağlantılı bir şekilde karşımıza çıkacaktır. Köleliğin toplumsal-tarihsel süreçteki rolüne bakıldığında, "Kölelik paradoksal bir biçimde Yunan polislerinde demokrasinin gelişimiyle daha çok önem kazanacaktır." (Yalçınkaya, 2011: 25). Yurttaşların, vakitlerini siyasete ayırabilmeleri için kölelerin çalıştırılması gerekmektedir. M.Ö. 5. yy' da madenlerde, yapımevlerinde, tarım alanlarında büyük ölçüde üretim köle emeğine dayanıyordu. Yurttaşların kültürel ve siyasal yaşam için ihtiyaç duyduğu zamanı köle emeği yaratmaktaydı (Ağaoğulları, 2013: 21). Bu noktada Atina'da köle, yurttaş oranları dikkat çekicidir. "Atina'nın Yunan dünyasındaki öneminin artışıla birlikte ekonomisi de canlanacak, kölecilik alıp başını gidecektir. İ.Ö. 312'de yapıldığı belirtilen bir nüfus sayımında, Attika ${ }^{4}$ nüfusu şöyle dağılmaktadır: 21000 yurttaş, 10000 metoikos, 400000 köle.” (Yalçınkaya, 2011: 39).

\footnotetext{
${ }^{4}$ Attika, Atina kentinin bulunduğu adanın adı
} 
Antik Yunan deneyiminin her aşamasında demokrasi yönetimi görülmemektedir. Kentin nasıl yönetileceği -demokrasi ya da oligarşideğişken bir yapıdadır. Hatta demokrasi dönemlerinde bile yurttaşlığın sınırlarının sürekli değişken olduğu görülmektedir (Canfora, 2010: 25-38). $\mathrm{Bu}$ anlamda, Atina kent devleti denildiğinde her döneminde, klasik demokrasi ile yönetilen bir tarihsel fotoğraf akla gelmemelidir.

\section{Siyasal Kurumlar ve İşleyişleri}

Yunan'da demokrasiyi meydana getiren diğer siyasal yapıların ve kurumların işleyişi üzerinde de durması yerinde olacaktır. Halk Meclisi (ekklesia); tüm sinıflardan oluşuyordu, Polemarkhos; başkomutan, Areopagus; görev süresi dolan arkhonlardl, Dörtyüzler Meclisi bule (daha sonra beşyüz kişiye yükselecektir), Yüksek Yönetici Memurlar; dokuz arkhon ve diğer önemli memurluklar söz konusuydu. Halk Mahkemeleri (heliaia), Halk meclisi yılda bir kez de Çanak Çömlek Mahkemesi ile yargılama hakkına da sahip oluyordu (Ağaoğulları, 2013: 33-40 ve Şenel, 2011:127-128). Deme, yerel düzeyde yönetimle ilgilenmekteydi. Atina'da bu anlamda çok sayıda Deme olduğu bilinmektedir (Çaha, 2010: 19-20). Yurttaşlığın soydan, ikamet şartı doğrultusunda değişmesiyle, halk içinde bulunduğu demenin adını kullanmaya başladı ve bu demeler yerel yönetimler olarak seçim bölgeleri işlevini görüyordu. Bule'nun 500 sandalyesi demeler arasında paylaştırılıyordu. Siyasal işleyiş̧ olarak ise, ekklesia-halk meclisinin işlevinin aslında siyasal iktidarı kullanmaktan öte halkın siyasal anlamda eğitim yeridir. Halk meclisi sayısal olarak da çok kalabalık olmasından önemli siyasal mevzuların diğer kurumlara bırakıldığı ve özellikle de bulenin güçlü bir konuma sahip olduğu belirtilmektedir (Ağaoğulları, 2013: 33-46). Bule meclisinde özellikle soylular ağırlık taşımaktaydılar. Yurttaşılı, belli sınıflara dağıtıldığı gibi bu sınıfların içinde de soylular özellikle siyasal alanda belirleyici oluyorlardı. Finley (2003:66) de benzer bir yaklaşımı ifade etmektedir. Eski Yunan'da görülen demokrasileri “...özellikle belli devlet görevlilerini seçmek gibi belli oranda bir katılım hakkı tanırken, karar alma sürecinde ağırlığı zenginlere tanımıştı." şeklinde nitelemektedir.

Bunların yanı sıra; Yunan demokrasisinin uygulandığı dönem itibariyle aldığ 1 eleştiriler mevcuttur. Siyasal yapıya dair, o dönem getirilen eleştirilerin çoğunun; siyasal haklara sahip olanların sayısının ve kapsamının daha da sınırlı hale getirilmeleri doğrultusunda olduğu gözlenmektedir. Yaşlı Oligark' $n^{5}$ Atinalıların Anayasası'nda ifade ettiği yoksul halkın yönetime dahil edilmesinin olumsuz yanlarını vurgularken, Ksenophon'un önerisi de, siyasal hak sahiplerinin sinırlanması gerektiği noktasına dayanmaktadır (Yalçınkaya, 2011; 48-49). Yunan'da demokrasiye getirilen eleştirilerin;

\footnotetext{
${ }^{5}$ Metnin yazarı tam olarak belli değildir. Bu nedenle Yaşlı Oligark denilmektedir.
} 
yönetimin sınırlı sayıda kişinin üstlenmesi gerektiği yönünde olduğu yani oligarşinin idealize edildiği görülmektedir.

Canfora, Yunan'da yurttaşlık çerçevesinin dönemsel olarak genişleyebildiğini fakat karşılaşılan duruma göre her defasında bunu tersine çevirecek, vatandaşlık sınırlarını daraltacak bir mekanizmanın toplumda (zenginler arasında) olduğunu ifade etmektedir. Yunan'da vatandaşlık sınırlarını genişletecek her girişim bu mekanizma ile karşılaşmaktadır.

Vatandaşlık kategorisini sınırlı sayıda tutma çabasının vatandaşlar arasında hep ağır bastığını ifade etmektedir (2010: 25-38) “.....yurttaş değerli yurttaşlık ayrıcalığı uğruna savaşmak için birbirlerine karşı silah kuşanmaya hazır olmalarına rağmen, yurttaşlığın 'camia' dışına genişlemesi fikrine oybirliğiyle karşı çıkıyorlardı." (Canfora, 2010; 35). Dolayısıyla yurttaşlık sınırlarının daraltılarak oligarşiye yönelik bir yapının oluşturulmaya çalışıldığı görülmektedir. Klasik demokrasiyi, mülk sahibi soylular arasında yapılan seçimler ya da müzakerelerin belirleyici olduğu ve vatandaşlık sınırlarının dönemsel olarak değişken olduğu bir demokrasi modeli olarak görmek gerekecektir.

Yunan kentinde, yönetimin yurttaşların yönetimi olarak biçimlendiğini görmekteyiz. Dönemsel olarak vatandaşlığın da kendi içinde farklılıklar gösterdiği ve siyasal yaşama katılma sınırlarının dönemden döneme değiştiği gözlenmektedir. Bu anlamda demokrasi dönemlerinde dahi yönetim tarzı olarak, oligarşi ve demokrasi arasında gidip gelmelerle karşımıza çıktığı görülür. Kurumlarının tarihsel süreç içinde durağan olmadığı, değişken olduğu göz önüne alınarak, Atina siyasal kurumlarının da sabit kalmadığı düşünülerek değerlendirilmelidir. Yurttaşlık sınırlarının daraltıldığı ölçüde oligarşiye yaklaştığı, sınırların genişlediği ölçüde de demokrasiye yaklaştığı bir yönetim olarak nitelenebilir.

Bunun yanında, Yunan toplumunda bulunan tüm insanlar göz önüne alındığında, halk kavramı belli sınırılıklar taşır. Bunun yanında zamana göre değişmekle birlikte, yurttaşlık sıfatına sahip olan herkes, aynı siyasal haklara da sahip değildir. Atina kent devletinde belli bir dönem görülen demokrasi deneyiminin, anlam olarak halk yönetimi kavramıla ilişkisine bakıldığında; halk kavramının toplumu kuşatma noktasında sınırlı tutularak, özellikle de mülk sahibi soylularla sınırlı tutularak açıklandığı görülmektedir. 


\section{Sonuç}

Toplumsal bir kurum olarak, "siyaset" kurumu, içinde bulunduğu toplumsal, tarihsel koşulların bir ürünü olarak ortaya çıkmaktadır. Yunan toplumunun; toplumsal yapısinin ele alınması sayesinde klasik demokrasi analitik bir şekilde değerlendirme imkanına kavuşabilir. Yunan toplumunda görülen klasik demokrasi deneyimini bu çerçevede ele almak ve açıklamak gerekmektedir.

Eski Yunan'da karşımıza siyasal kavramlar ile bu kavramların işleyiş mekanizmaları ve uygulamalar arasındaki ilişkiyi kurarak çalışmada demokrasi ortaya konmaya çalışıldı. Dolayısıyla siyasal kavramlar ve toplumsal ve tarihsel ilişkiler çerçevesinde; yurttaş ve siyasal katılım, halk... gibi siyasal ve toplumsal süreçler incelenmeye çalışlmıştır. Toplumsal sınıflar anlamında, Yunan toplumu ele alındığında, belli dışlamaların var olduğu özellikler göstermektedir. Yunan toplumunda, en geniş çerçeve olarak, toplum kavramını ifade edersek, toplumun (kavramının) içinde olmasına rağmen halk kavramına dahil edilmeyen, köleler söz konusudur. $\mathrm{Bu}$ anlamda halk ve köleler ayrı ayrı kategorileri oluşturmaktadırlar. $\mathrm{Bu}$ durumun yanı sıra, halk kategorisi ile yurttaş aynı anlama gelmemektedir. Bu noktada modern demokrasinin de bir kavramı olan "yurttaş" ile Yunan toplumundaki yurttaş kavramının farklılığını vurgulamak gerekmektedir.

Günümüzün modern demokrasilerinde; "yurttaş", "halk", "toplum" kavramları birbirini kapsamaktadır. Toplumun-halkın tamamı vatandaş kitlesini oluşturur. Oysa, Yunan toplumunda yeralan farklı kategorilerden biri olarak yurttaş kavramı, toplumun tamamı (kadınlar, yabancılar, fakirler) göz önüne alındığında, çok sınırlı bir kesime yurttaş sıfatıyla siyasal haklar tanımaktadır. Günümüzün "yurttaş” kavramı ile olan farklılığı temelinde açıklanması yerinde olacaktır. Yunan toplum yapısı ekseninde ve "klasik demokrasinin" ele alınması yoluyla; "klasik demokrasi" ve "modern demokrasinin" dayandığı farklılıklar da netleşmektedir.

Bunun dışında, Yunan toplumunda; yönetsel, askeri, kültürel, sosyal mevzularda alg1 kente odaklı bir yapı arz etmektedir. Yunan toplumunda her mesele kent ile ilişkili olmak durumundadır. "Bireysellik" anlayışı henüz gelişmemiştir. Bu durumu "özgürlük" kavramının Yunan toplumundaki anlamından da çıkarmak mümkündür. "Özgürlük" Yunan toplumunda başka bir topluma savaş açma anlamında özgür olmayı kasteder. Kimlik olarak sadece kent kavramı vardır. Toplumda, kent ve yönetim odaklı bir algının varlığının altını çizmek gerekmektedir.

Sonuç olarak, Yunan bir yurttaşlar yönetimi olarak karşımıza çıkmaktadır. Bununla birlikte yurttaş ve siyasal katılım kavramlarına; Atina kentinde, toplumsal olarak dahil edilmeyenler (kadınlar, yabancılar, köleler, yoksullar) üzerinden değil de, bu anlama toplumsal olarak sadece dahil 
edilenler yani yurttaşlar çerçevesinde işleyen bir siyasal organizasyon olarak klasik demokrasi ifade edilmelidir.

\section{Kaynakça}

Arblaster, Anthony. (1999), Demokrasi, Çev. Nilüfer Yılmaz, Ankara: Doruk Yayımcılık

Ağaoğullari, Mehmet Ali. (2013), Kent Devletinden Imparatorluğa, 7. Bask1, İmge Kitabevi, Ankara

Aristoteles. (2010), Politika, çev. Ersin Uysal, 2 basım, İstanbul: Dergah Yayınları

Arnhart, Larry. (2008), Siyasi Düşünce Tarihi Plato'dan Rawls'a, çev. Ahmet Kemal Bayram, Ankara: Adres Yayınları

Canfora, Luciano. (2010), Avrupa'da Demokrasi: Bir Ideolojinin Tarihi, çev. Neşenur Domaniç ve Nusret Avhan, İstanbul: Literatür Yayıncılık,

Çaha, Ömer. (2010), Siyasi Düşüncelere Giriş, 2. Basım, İstanbul: Dem Yayınları

Finley, Moses I.. (2003), Antik ve Modern Demokrasi, çev. Deniz Türker, Ankara: Ayraç Yayınevi

Hobbes, Thomas.(2013), Leviathan, çev. Semih Lim, 11. Baskı, İstanbul: Yap1 Kredi Yayınları

Platon. (2002), Devlet, çev. Hüseyin Demirhan, İstanbul: Sosyal Yayınlar

Sartori, Giovanni. (1996), Demokrasi Teorisine Geri Dönüş, çev. Tunçer Karamustafaoğlu ve Mehmet Turhan, Ankara: Yetkin Yayınları

Şenel, Alaeddin. (2011), Siyasal Düşünceler Tarihi: Tarih Öncesinde İlkçă̆da Ortaçağda ve Yeniçă̆da Toplum ve Siyasal Düşünüş, Ankara: Bilim Sanat Yayınları

Yalçinkaya, Ayhan. (2011), "Yunan Uygarlığı İçinde Polis ve Siyaset", Sokrates'ten Jakobenlere Batı'da Siyasal Düşünceler, der. Mehmet Ali Ağaoğulları, 2. baskı, İstanbul: İletişim Yayınları 